\title{
Highly Sensitive Detection of Monosaccharides on Microchip Electrophoresis Using pH Discontinuous Solution System
}

\author{
Hideya NaGaTA, ${ }^{* 1 \dagger}$ Tamitake ITOH, ${ }^{* 1}$ Yoshinobu BABA, ${ }^{* 1, * 2, * 3, * 4}$ and Mitsuru IshIKAWA ${ }^{* 1}$ \\ *1 Health Technology Research Center, National Institute of Advanced Industrial Science and Technology (AIST), \\ 2217-14 Hayashi, Takamatsu 761-0395, Japan \\ *2 Department of Applied Chemistry, Graduate School of Engineering, Nagoya University, \\ Furo-cho, Chikusa, Nagoya 464-8603, Japan \\ *3 MEXT Innovative Research Center for Preventive Medical Engineering, Nagoya University, \\ Furo-cho, Chikusa, Nagoya 464-8603, Japan \\ *4 Plasma Nanotechnology Research Center, Nagoya University, Furo-cho, Chikusa, Nagoya 464-8603, Japan
}

\begin{abstract}
We improved the detection sensitivity of neutral and amino monosaccharides labeled with 2-aminoacridone by a factor of 19.6 - 48.7 and 44.4 - 65.9, respectively, with no deterioration in separation resolution, using a $\mathrm{pH}$ discontinuous solution system instead of the conventional solution system. The $\mathrm{pH}$ discontinuous solution system is simple, using only a borate solution at $\mathrm{pH} 6.0$ as a sample solution and a Tris-borate solution at pH 9.3 as a separation solution, enabling an enhancement of the sensitivity by monosaccharide stacking. This technique is fully compatible with conventional microchip electrophoresis, thereby allowing us to develop efficient tools for highly sensitive and resolved detection of monosaccharides.
\end{abstract}

(Received December 22, 2009; Accepted May 16, 2010; Published July 10, 2010)

\section{Introduction}

Carbohydrates of glycoproteins and glycolipids perform various functions on cell surfaces, from regulation of protein hydrophilicity to highly specific receptor interactions. ${ }^{1,2}$ Many functionally important oligosaccharides, carbohydrate chains of glycoproteins, and glycolipids naturally occur in extremely small quantities. To analyze small quantities of carbohydrates, which exhibit similar chemical properties in complex structures, we require increasingly sophisticated methods for separation and analysis, while maintaining or exceeding the standards of the current sensitivity and selectivity techniques.

Microchip electrophoresis (MCE) is one of the most successful miniaturized analysis systems, allowing minimal sample and reagent consumption, quick analysis, efficient separation, and automation of manual routine work. ${ }^{3-5}$ This technique has been successfully used to analyze DNA fragments, ${ }^{6}$ aminoacids, ${ }^{7}$ proteins, ${ }^{8,9}$ and carbohydrates. ${ }^{10-13}$ However, a mixture of either neutral or amino monosaccharides is difficult to separate into its components by conventional electrophoresis because of their similarities in structure, molecular weight, and electric charge. ${ }^{11}$ We have reported a conformational separation technique for monosaccharides in polymer microchips. The technique enables the successful separation of each monosaccharide according to subtle differences in the chemical stability of the complex between the hydroxyl residue in the monosaccharide and borate ions in a $200 \mathrm{mM}$ borate solution at $\mathrm{pH} 8.5 .^{11}$ The use of $\mathrm{pH} 8.5$

† To whom correspondence should be addressed.

E-mail: hideyan@shimadzu.co.jp is essential for the high-resolution separation of monosaccharides in the conformational separation technique. The technique has been used for many applications. ${ }^{12,13}$ However, the sensitivity of conformational separation is inferior to that of conventional capillary electrophoresis (CE). ${ }^{14}$ Therefore, an improvement in the monosaccharide detection sensitivity is highly desirable for enhancing the utility of conformational separation.

Laemmli $^{15}$ improved the resolution in the separation of proteins using a discontinuous buffer system in sodium dodecyl sulfate poly(acrylamide) gel electrophoresis. We reported that a discontinuous buffer system for DNA separation, in which both the $\mathrm{pH}$ and ions in a sample solution are different from those in a separation solution, is compatible with MCE in resolution because the boundary between the sample and separation solutions is readily established in microchannels. ${ }^{16}$ Thus, the discontinuous buffer system ${ }^{15,16}$ motivates us to improve the sensitivity to the detection and resolution of monosaccharides using a discontinuous solution system for monosaccharide separation. In the current work, we separated a mixture of five neutral monosaccharides and a mixture of two amino monosaccharides with improved sensitivity and acceptable resolution. The essential elements for an improved detection sensitivity of the seven monosaccharides in acceptable resolution are adding tris(hydroxymethyl)aminomethane (Tris) to a separation solution at $\mathrm{pH} 9.3$ and changing the $\mathrm{pH}$ from 9.3 to 6.0 in the sample solution. We assume that the monosaccharide detection sensitivity is enhanced by sample stacking of monosaccharides caused by a difference between the effective mobility of borate ions in a sample solution and that in a separation solution. The $\mathrm{pH}$ discontinuous solution system, in which only the $\mathrm{pH}$ of the sample solution is different from that 
of the separation solution, improved the detection sensitivity of the neutral and amino monosaccharides by a factor of $19.6-48.7$ and 44.4 - 65.9, respectively, compared with the conformational separation solution system. The resolution $(0.93-1.74$ and 4.44) of two adjacent peaks of the five neutral and two amino monosaccharides in the $\mathrm{pH}$ discontinuous solution system was comparable to that $(0.91-1.74$ and 4.14 , respectively) in the conventional $\mathrm{pH} 8.5$ solution system.

\section{Experimental}

\section{Reagents and chemicals}

Five neutral monosaccharides (D-glucose (Glc), D-mannose (Man), D-galactose (Gal), L-fucose (Fuc), and D-xylose (Xyl) and two amino monosaccharides, $N$-acetyl-D-glucosamine (GlcNAc) and $N$-acetyl-D-galactosamine (GalNAc)) were obtained from Sigma (Tokyo). A sieving matrix methylcellulose (MC, $M_{\mathrm{W}} 86000 \mathrm{Da}, 2 \mathrm{wt} \%$ aqueous solution, $4000 \mathrm{mPa} \mathrm{s}$ ) was also obtained from Sigma (Tokyo) and was used as a coating reagent. ${ }^{17}$ A fluorescent reagent, 2-aminoacridone (AMAC), having an excitation wavelength of $425 \mathrm{~nm}$ and an emission wavelength of $531 \mathrm{~nm}$, and sodium cyanoborohydrate were purchased from Sigma. All chemicals were of the highest grade commercially available.

\section{Sample preparation and buffer solution}

All of the monosaccharides were labeled with AMAC by a reductive amination method, previously reported. ${ }^{11}$ A mixture of five neutral, AMAC-labeled monosaccharides (Glc, Man, Gal, Fuc, and Xyl) or a mixture of two amino monosaccharides (GlcNAc and GalNAc) was dissolved in a sample solution of $200 \mathrm{mM}$ borate, $\mathrm{pH} 5.0-10.0$, and was separated using a separation solution, $0.5 \mathrm{wt} \% \mathrm{MC}, 0-300 \mathrm{mM}$ Tris-200 mM borate, $\mathrm{pH} 5.0-10.0$. A conventional running buffer ${ }^{11-13}$ including cellulose polymer additives was prepared by adding MC to $200 \mathrm{mM}$ boric acid and stirring slowly until the solution appeared to be homogeneous and transparent. ${ }^{18}$

\section{Apparatus}

A mixture of monosaccharides was separated into each component using a PMMA microchip (i-chip 3 DNA, Hitachi Chemical, Tokyo) and an MCE machine (SV1100 Microchip CE system, Hitachi, Tokyo). An SV1100 machine was equipped with a light-emitting diode for excitation at $470 \mathrm{~nm}$ and a confocal fluorescence detection system for the fluorescence maximum at $\sim 580 \mathrm{~nm}$. The specifications of the PMMA microchips used in the current work were described in previous reports. ${ }^{8,911,16}$ In brief, a chip includes three pairs of cross channels of $100 \mu \mathrm{m}$ in width, $30 \mu \mathrm{m}$ in depth, and $30 \mathrm{~mm}$ in effective separation length. The lengths from the cross point to the sample reservoir (SR), sample waste (SW), buffer reservoir (BR), and buffer waste (BW) are 5.25, 5.25, 6.50, and $38.0 \mathrm{~mm}$, respectively.

\section{Microchip electrophoresis}

Microchip electrophoresis was conducted using an MCE system (SV1100, Hitachi High-Technologies, Tokyo). A mixture of monosaccharides was loaded into SR, and a separation solution was loaded in the other three reservoirs (SW, $\mathrm{BR}$, and BW). Applying $200 \mathrm{~V}$ to SW for $90 \mathrm{~s}$ with the other three reservoirs grounded allowed monosaccharides to migrate into the injection channel. During separation, BR was grounded, both SR and SW were maintained at $130 \mathrm{~V}$, and BW was set at $750 \mathrm{~V}$ to produce an electric field of $165 \mathrm{~V} \mathrm{~cm}^{-1}$, the maximum electric field of the MCE system, in the separation channel. Data were acquired using software (SV1100a Ver. 1.10, Hitachi High Technologies, Tokyo).

\section{Results and Discussion}

The present study consisted of four frameworks. First, we examined the effect of the $\mathrm{pH}$ in the borate solution on the separation of neutral monosaccharides using a continuous solution system, to compare it with a discontinuous solution system. We found that, in a continuous solution system, the monosaccharide fluorescence intensity increased by only $56-67 \%$ by varying the $\mathrm{pH}$. Second, we proposed a $\mathrm{pH}$ discontinuous solution system to improve the fluorescence intensity of all monosaccharides. Third, we observed electropherograms of the five neutral monosaccharides, separated using a $\mathrm{pH}$ discontinuous solution system, to identify the effectiveness of a proposed $\mathrm{pH}$ discontinuous solution system in the stacking of monosaccharides. We found that the fluorescence intensity of the five monosaccharides increased dramatically using a $\mathrm{pH}$ discontinuous solution system, although Glc and Man were not separated. Last, we observed the effect of Tris concentrations on the separation of five neutral monosaccharides in the $\mathrm{pH}$ discontinuous solution system to separate Glc and Man. The five neutral monosaccharides were finally separated using a $200 \mathrm{mM}$ Tris-borate solution as a separation solution. Two amino monosaccharides were also separated using the $\mathrm{pH}$ discontinuous solution system. The separation of the amino monosaccharides is described briefly in Table 1 and in Fig. S2 in SI. We improved the detection sensitivity of all the monosaccharides without any deterioration in separation resolution.

Effect of $p H$ in borate solution upon separation of neutral monosaccharides using conventional continuous solution system A mixture of five neutral monosaccharides (Glc, Man, Gal, Fuc, and Xyl) was separated by MCE using a conventional continuous solution system, in which the $\mathrm{pH}$ and the concentration of the sample solution were the same as those of the separation solution. We selected borate ions for the sample and separation solutions. We then observed electropherograms of the neutral monosaccharides labeled with AMAC using a continuous borate solution $(200 \mathrm{mM})$ system at $\mathrm{pH}$ 5.0, 6.0, 7.0, $8.5,9.0,9.3,9.5$, and 10.0. Figure $1 \mathrm{~A}$ shows that at $\mathrm{pH} 5.0$ the monosaccharides were not migrated; at $\mathrm{pH} 7.0$, Glc, Man, and Xyl were not separated; at $\mathrm{pH} \mathrm{8.5,} \mathrm{the} \mathrm{five} \mathrm{neutral}$ monosaccharides were separated; and for $\mathrm{pH} 9.0-10.0$, Glc and Man were not separated. Glc and Man were not separated, except at $\mathrm{pH} 8.5$ because they have similar conformations. ${ }^{11,19,20}$ The difference between Glc and Man is the number of possible threo-conformations. For this reason, the separation of Glc and Man is difficult and will be affected by delicate experimental conditions, such as the $\mathrm{pH}$, concentration of borate ions and additives.

We observed that the fluorescence intensity of the separated monosaccharides (Gal, Fuc, and $\mathrm{Xyl}$ ) depended on the $\mathrm{pH}$ of the borate solution. Figure 1B shows that the fluorescence intensity of Gal, Fuc, and Xyl increased between $\mathrm{pH} 9.0$ and 9.3 and decreased as the $\mathrm{pH}$ increased from 9.3 to 10.0. In addition, the concentration of borate ions, $C_{\mathrm{B}^{-}}$, i.e., tetrahydroxyborate ions, which is given by Eq. (1), increased between $\mathrm{pH} 9.0$ and 9.3:

$$
C_{\mathrm{B}^{-}}=\frac{C^{*}{ }_{\mathrm{B}}}{10^{\mathrm{pKa}-\mathrm{pH}}+1}=\frac{C^{*}{ }_{\mathrm{B}}}{10^{9.24-\mathrm{pH}}+1},
$$




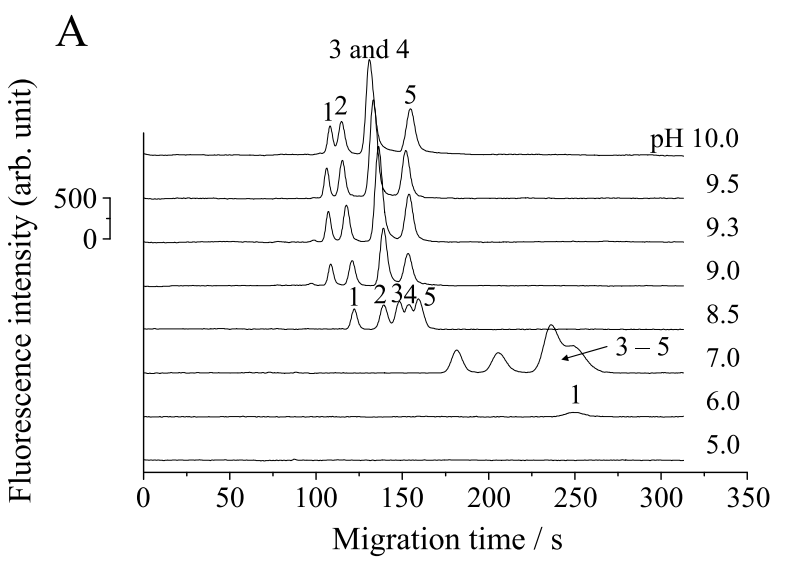

$\mathrm{B}$
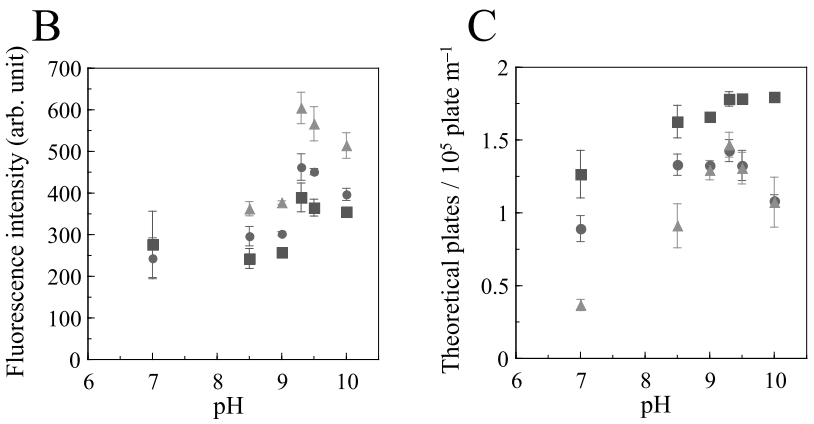

Fig. 1 Effect of $\mathrm{pH}$ of borate solution on MCE separation of neutral monosaccharides. (A) Electropherograms. (B) Fluorescence intensity and (C) theoretical plates of separated monosaccharides (Gal, Fuc, and $\mathrm{Xyl}$ ). The $\mathrm{pH}$ of the borate solution is shown in each electropherogram. Monosaccharide peaks are numbered as follows: 1, Gal; 2, Fuc;

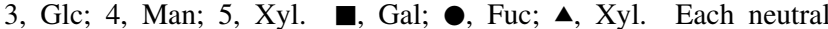
monosaccharide was labeled with AMAC and the concentration of each monosaccharide was $20 \mu \mathrm{M}$. The applied electric field strength was $165 \mathrm{~V} \mathrm{~cm}^{-1}$.

where $C^{*}{ }_{\mathrm{B}}$ is the total concentration of borate species, $\mathrm{p} K_{\mathrm{a}}$ the acidic dissociation constant of boric acid; $\mathrm{p} K_{\mathrm{a}}=9.24$ at $25^{\circ} \mathrm{C}$. Thus, the use of a $200 \mathrm{mM}$ borate solution at $\mathrm{pH} 9.0$ and 9.3 provides $C_{\mathrm{B}^{-}}=73.1$ and $106.9 \mathrm{mM}$, respectively, according to Eq. (1). Moreover, hydroxide ions and counter ions increased with increasing $\mathrm{pH}$. We observed that the electric current between $\mathrm{BR}$ and $\mathrm{BW}$ depended upon the $\mathrm{pH}$ of the separation solution during MCE separation. Figure 2 shows that an electric current passing through the separation solution increased with increasing $\mathrm{pH}$. The increased borate ions, hydroxide ions, and counter ions increase an electric current passing through the separation solution; an associated temperature increase is inevitable. Hoffstetter-Kuhn et al. ${ }^{2}$ reported that the increased temperature reduces the viscosity of the separation solution, leading to an increased monosaccharide mobility and an increased quantity of the monosaccharide injected. Thus, the increase in the fluorescence intensity between $\mathrm{pH} 9.0$ and 9.3 was likely due to an increase in the quantity of the injected monosaccharides. Similarly, a decrease in the fluorescence intensity of the three monosaccharides from $\mathrm{pH} 9.3$ to 10.0 would be ascribable to the sample zone being broadened by decreased viscosity of the separation solution due to further increased temperature (Fig. 2).

We observed that the number of theoretical plates for the three separated monosaccharides depended on the $\mathrm{pH}$ of the borate solution. Figure $1 \mathrm{C}$ shows that the number of theoretical plates

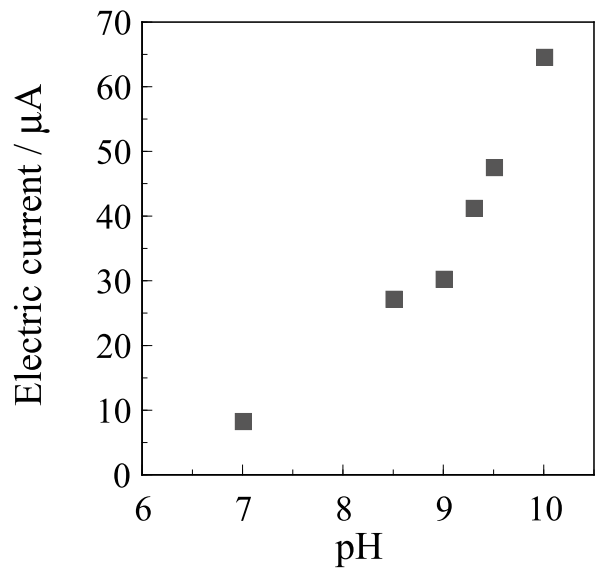

Fig. 2 Effect of electric current between $\mathrm{BR}$ and $\mathrm{BW}$ on $\mathrm{pH}$ of separation solution during MCE separation. The applied electric field strength was $165 \mathrm{~V} \mathrm{~cm}^{-1}$. Each value is the average for an electric current during MCE separation.

for the monosaccharides at $\mathrm{pH} 9.3$ was the highest in the $\mathrm{pH}$ range $6.0-10.0$, and it decreased with increasing $\mathrm{pH}$ from 9.3 to 10.0 , except in the case of Gal. This result indicates that the sample zone of the monosaccharides is diffused due to the decreasing viscosity of the separation solution from increased temperature, which is induced by Joule heat from the increased number of borate ions. The steady number of theoretical plates for Gal, insensitive to Joule heat, is ascribable to Gal having the highest mobility among the five monosaccharides in the microchannel; because Gal spends less time in the separation channel, it takes less time to diffuse.

We found that a change in the $\mathrm{pH}$ in a continuous solution is unsuitable for our purpose of remarkably improving the detection sensitivity of monosaccharide. Even the highest fluorescence intensities of Gal, Fuc, and Xyl, measured at $\mathrm{pH}$ 9.3 , were only $1.60,1.56$, and 1.67-times higher than those at $\mathrm{pH} 8.5$, respectively (Fig. 1B). However, the use of $\mathrm{pH} 9.3$ for a separation solution is crucial for improving the fluorescence intensity and the number of theoretical monosaccharide plates, although Glc and Man were not separated. A technique for separating Glc and Man is the addition of Tris to a separation solution, and is described in "Improvement in resolution using Tris."

Mechanism of stacking monosaccharides using pH discontinuous solution system

We propose a $\mathrm{pH}$ discontinuous solution system to improve the fluorescence intensity of all monosaccharides. Figure 3 shows a proposed mechanism of monosaccharide stacking in a $\mathrm{pH}$ discontinuous solution system. In the sample loading phase (Fig. 3A), a separation solution at $\mathrm{pH} 9.3$ at the cross point of two microchannels is replaced with a monosaccharide solution at $\mathrm{pH}$ 6.0. In the sample separation phase (Fig. 3B), complexes between monosaccharides and borate ions are injected into the separation channel and form a sample zone. The application of high voltage to the separation channel generates an electric field step from the sample zone to BW through the separation solution. In a sample solution at $\mathrm{pH} 6.0$, a small amount of boric acid is dissociated into borate ions; thus, its effective mobility is lower than that of negatively charged complexes between monosaccharides and borate ions. The use of a $200 \mathrm{mM}$ borate solution at $\mathrm{pH} 6.0$ provides $C_{\mathrm{B}^{-}}=0.12 \mathrm{mM}$ 


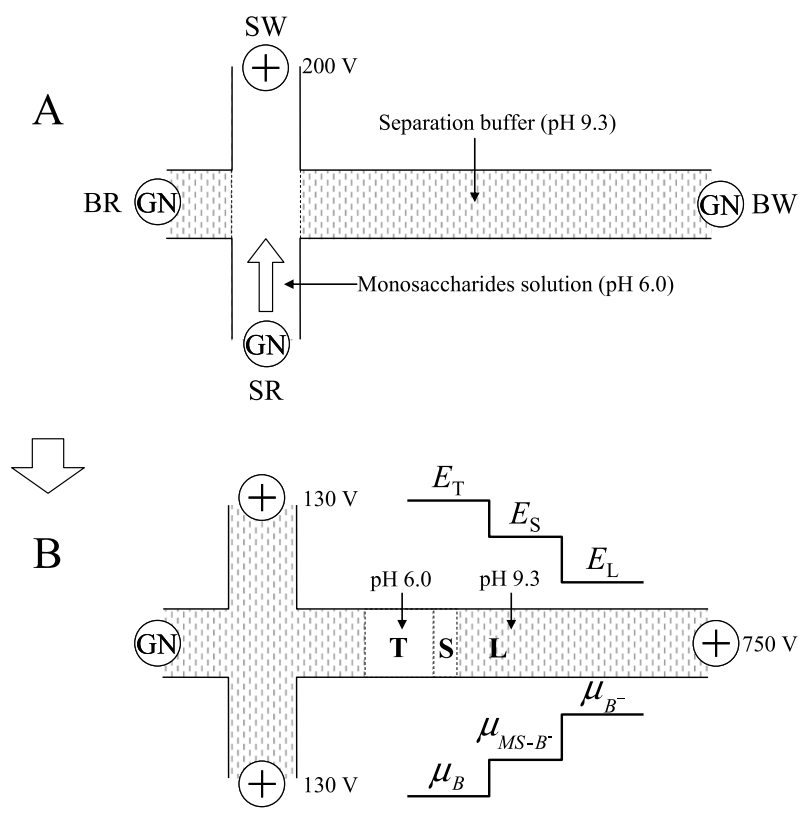

Fig. 3 Proposed mechanism for stacking of monosaccharides in a $\mathrm{pH}$ discontinuous solution system on a chip. (A) Sample loading phase and (B) sample separation phase. Symbols: T (terminating ion, i.e., borate ion at $\mathrm{pH}$ 6.0), $\mathrm{S}$ (sample ion, i.e., complexes between monosaccharides and borate ions), $\mathrm{L}$ (leading ion, i.e., borate ion at $\mathrm{pH}$ 9.3), $E$ (applied electric field), and $\mu$ (mobility of ionic species). Subscripts: B (boric acid), MS-B ${ }^{-}$(complex between monosaccharides and borate ions), and $\mathrm{B}^{-}$(borate ion, i.e., tetrahydroxyborate ion).

using Eq. (1). In contrast, in a separation solution at $\mathrm{pH} 9.3$ $\left(C_{\mathrm{B}^{-}}=106.9 \mathrm{mM}\right)$, borate ions, i.e., tetrahydroxyborate ions, have a mobility higher than that of complexes between monosaccharides and borate ions. In other words, at $\mathrm{pH} 6.0$ borate ions become terminating ions against complexes between monosaccharides and borate ions, but at $\mathrm{pH} 9.3$ they become leading ions against the complexes. From the principle of a discontinuous solution system, it follows that the concentration of complexes between monosaccharides and borate ions in the sample zone changes until it is adjusted to a definite ratio controlled by the concentration of the leading ion, i.e., tetrahydroxyborate ion. Each complex between monosaccharides and borate ions migrates according to its own mobility. Thus, monosaccharides will be stacked by a $\mathrm{pH}$ discontinuous solution system.

Effect of different $p H$ values between sample and separation solution on separation of neutral monosaccharides using $p H$ discontinuous solution system

To evaluate the proposed $\mathrm{pH}$ discontinuous solution system in the stacking of monosaccharides, we observed electropherograms of the five neutral monosaccharides separated by MCE at $\mathrm{pH} 6.0$ in a $200 \mathrm{mM}$ borate sample solution and at $\mathrm{pH} 8.5-10.0$ in a $200 \mathrm{mM}$ borate separation solution use. Figure 4A shows that the fluorescence intensity of the five monosaccharides was higher than that in Fig. 1A, although Glc and Man were not separated again. Note that the concentration of the monosaccharides in Fig. 4 is $2 \mu \mathrm{M}$, in contrast to $20 \mu \mathrm{M}$ in Fig. 1. The fluorescence intensity of the monosaccharides in the $\mathrm{pH}$ discontinuous solution system was remarkably increased, and was higher than that in the continuous solution system by a factor of 10 . We consider that the stacking of monosaccharides
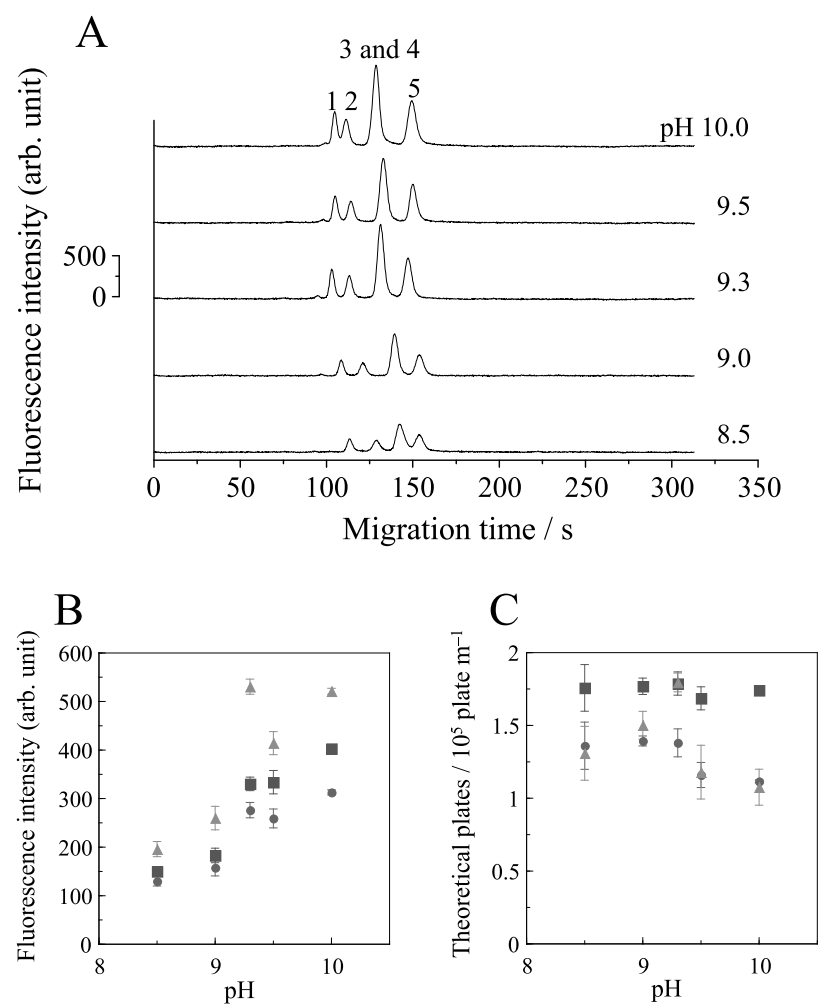

Fig. 4 Separation of neutral monosaccharides using $\mathrm{pH}$ discontinuous solution system. (A) Electropherograms. (B) Fluorescence intensity and (C) theoretical plates of separated monosaccharides (Gal, Fuc, and Xyl). The $\mathrm{pH}$ of the separation solution is shown in each electropherogram. The monosaccharide peaks are numbered as follows: 1, Gal; 2, Fuc; 3, Glc; 4, Man; 5, Xyl.

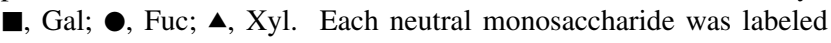
with AMAC and the concentration of each monosaccharide was $2 \mu \mathrm{M}$. Applied electric field strength was $165 \mathrm{~V} \mathrm{~cm}^{-1}$.

occurs in the $\mathrm{pH}$ discontinuous borate solution system because it is unlikely that the fluorescence intensity, which fundamentally depends on the concentration of loaded monosaccharides, was increased by a factor of 10 without stacking.

We examined the separated monosaccharides' dependence on the $\mathrm{pH}$ of a separation solution for the fluorescence intensity. Figure 4B shows that the fluorescence intensity of each monosaccharide increased to between $\mathrm{pH} 9.0$ and 9.3. The reason for this increase is the same as that in Fig. 1B. The efficiency in monosaccharide stacking at $\mathrm{pH} 10.0$ is higher than that at $\mathrm{pH} 9.3$ because the difference in the effective mobility of the borate ion between $\mathrm{pH} 6.0$ and $10.0\left(C_{\mathrm{B}^{-}}=170.4 \mathrm{mM}\right)$ is larger than that between $\mathrm{pH} 6.0$ and $9.3\left(C_{\mathrm{B}^{-}}=106.9 \mathrm{mM}\right)$.

The number of theoretical plates for the three separated monosaccharides depends on the $\mathrm{pH}$ of the separation solution. Figure $4 \mathrm{C}$ shows that the number of theoretical plates for all of the monosaccharides, except for Gal, was decreased with increasing the $\mathrm{pH}$ from 9.3 to 10.0 , and the number of theoretical plates for Gal, Fuc, and Xyl at pH $9.3\left(1.79,1.38\right.$, and $1.79 \times 10^{5}$ plates $\mathrm{m}^{-1}$, respectively) was $1.03,1.24$, and 1.67-times larger than that for each monosaccharide at $\mathrm{pH} 10.0(1.74,1.12$, and $1.08 \times 10^{5}$ plates $\mathrm{m}^{-1}$, respectively). At $\mathrm{pH} 9.5$ and 10.0 , the sample zone of the monosaccharides was similarly broadened due to decreased viscosity. The effect of Joule heat on the diffusion of the monosaccharides at $\mathrm{pH} 9.3$ was smaller than that at $\mathrm{pH} 9.5$ and 10.0. In addition, fluorescence is generally 


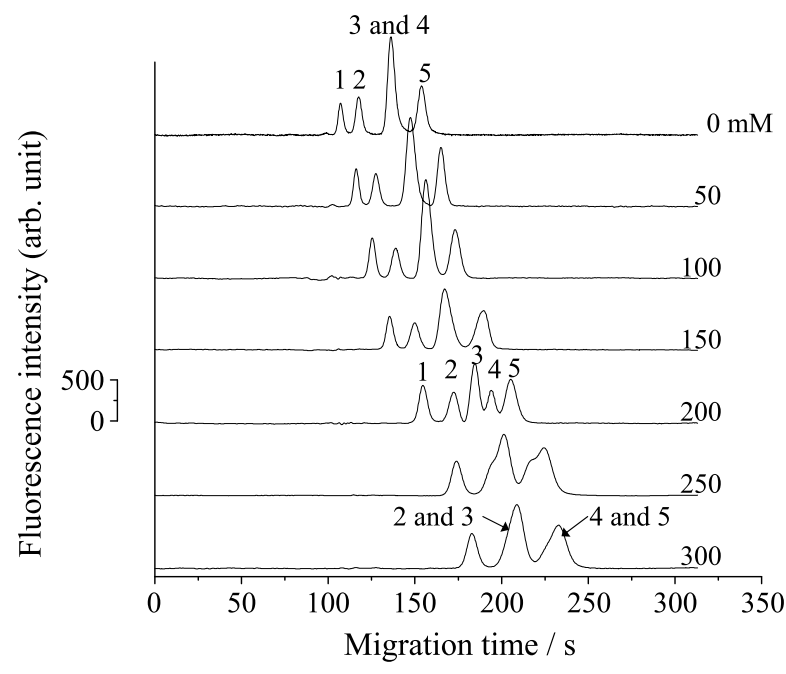

Fig. 5 Effect of Tris concentrations on MCE separation of neutral monosaccharides in $\mathrm{pH}$ discontinuous solution system. The concentrations of Tris are shown in each electropherogram. Monosaccharide peaks are numbered as follows: 1, Gal; 2, Fuc; 3, Glc; 4, Man; 5, Xyl. Each neutral monosaccharide was labeled with AMAC and the concentration of each monosaccharide was $2 \mu \mathrm{M}$. The applied electric field strength was $165 \mathrm{~V} \mathrm{~cm}^{-1}$.

quenched by temperature. Thus, the higher Joule heat at $\mathrm{pH} 9.5$ and 10.0 than at $\mathrm{pH} 9.3$ is undesirable for the detection of fluorescence. Indeed, we found that a separation solution at $\mathrm{pH} 9.3$ was the best to enhance both the sensitivity to the detection and resolution of the monosaccharides. In the present study, we selected a separation solution at $\mathrm{pH} 9.3$ from the range of separation solutions at $\mathrm{pH} 8.5-10.0$.

Incidentally, a pH 7.0 borate sample solution enhanced the fluorescence intensity of the separated monosaccharides less than did a sample solution at pH 6.0 (Fig. S1 in SI). Moreover, at $\mathrm{pH} \mathrm{5.0,} \mathrm{the} \mathrm{monosaccharides} \mathrm{were} \mathrm{not} \mathrm{migrated,} \mathrm{and} \mathrm{thus}$ they were not detected (data not shown). Therefore, we selected a borate solution at $\mathrm{pH} 6.0$ as a sample solution.

\section{Improvement in resolution using Tris}

Here, we address the issue of separating of Glc and Man. Our accumulated experience aroused the possibility that the resolution of monosaccharides is improved by the addition of Tris to a separation solution (unpublished data). To improve the separation of monosaccharides Glc and Man, we added $0-300 \mathrm{mM}$ Tris to the separation solution, $0.5 \mathrm{wt} \% \mathrm{MC}$, $200 \mathrm{mM}$ borate, $\mathrm{pH} 9.3$. We observed the effect of the Tris concentrations on the MCE separation of neutral monosaccharides in the $\mathrm{pH}$ discontinuous solution system. Figure 5 shows that Glc and Man were not separated at concentrations of Tris $0-150 \mathrm{mM}$. Although the migration time of the samples was longer than that shown in Figs. 1A and $4 \mathrm{~A}$, the resolution was clearly improved with increasing concentration of Tris up to $200 \mathrm{mM}$. The difference in the migration time between Fuc and Glc and that between Man and Xyl narrowed with the increasing concentration of Tris up to $250 \mathrm{mM}$. Fuc and Glc as well as Man and Xyl, were not separated at $300 \mathrm{mM}$. The five monosaccharides were finally separated using a $200 \mathrm{mM}$ Tris-borate solution as a separation solution. The migration times of the monosaccharides were affected by the concentration of Tris, possibly because Tris ions interact with the complexes between monosaccharides and
Table 1 Reproducibility of the mobility and LOD of monosaccharide derivatives ${ }^{\mathrm{a}}$

\begin{tabular}{lcc}
\hline \multicolumn{1}{c}{ Monosaccharide } & $\begin{array}{c}\text { Average mobility } \\
(\mathrm{RSD} \%)^{\mathrm{b} /} \\
10^{-4} \mathrm{~cm}^{2} \mathrm{~V}^{-1} \mathrm{~s}^{-1}\end{array}$ & LOD $/ \mu \mathrm{M}$ \\
\hline Neutral & & \\
$\quad$ D-Galactose & $1.17(0.62)$ & 0.052 \\
L-Fucose & $1.05(0.65)$ & 0.051 \\
D-Glucose & $0.98(0.60)$ & 0.025 \\
D-Mannose & $0.93(0.52)$ & 0.031 \\
D-Xylose & $0.88(0.54)$ & 0.032 \\
Amino & & \\
$\quad N$-Acetyl-D-glucosamine & $0.95(0.76)$ & 0.015 \\
$N$-Acetyl-D-galactosamine & $0.68(0.81)$ & 0.035 \\
\hline a. Conditions: electric field, $165 \mathrm{~V} \mathrm{~cm}^{-1}, \mathrm{pH}$ discontinuous solution \\
system. \\
b. RSD, $n=3$. \\
c. LOD, $S / N$ of 3.
\end{tabular}

borate ions. Also, the two monosaccharides, Fuc and Man, were relatively more affected than the others, possibly because the interaction depends on the conformation of the complex.

In the $\mathrm{pH}$ discontinuous solution system, the resolutions of two adjacent peaks of monosaccharides $R_{1 / 2}, R_{2 / 3}, R_{3 / 4}$, and $R_{4 / 5}$ were $1.74,1.23,0.96$, and 0.93 , respectively. Here, $R_{1 / 2}, R_{2 / 3}$, $R_{3 / 4}$, and $R_{4 / 5}$ mean the resolution of Gal and Fuc, Fuc and Glc, Glc and Man, and Man and Xyl, respectively. In the conventional solution system in Ref. 11, the best resolutions of the five monosaccharides $\left(R_{1 / 2}, R_{2 / 3}, R_{3 / 4}\right.$, and $\left.R_{4 / 5}\right)$ are $1.74,0.96,0.95$, and 0.91 , respectively. The separation resolution of monosaccharides in the $\mathrm{pH}$ discontinuous solution system is comparable to that in the conventional solution system.

Moreover, we separated a mixture of two amino monosaccharides, GlcNAc and GalNAc, by MCE using the $\mathrm{pH}$ discontinuous solution system (Fig. S2 in SI). Table 1 summarizes the reproducibility of the mobility and the limit of detection (LOD) of five neutral monosaccharides and two amino monosaccharides. A high RSD of mobility, within $0.81 \%$, was obtained for all monosaccharides. The LOD values of the five monosaccharides (Glc, Man, Gal, Fuc, and Xyl) were decreased by factors of 19.6, 21.9, 34.2, 32.4, and 48.7, respectively, using the current $\mathrm{pH}$ discontinuous solution system: $0.025 \mu \mathrm{M}$ for Glc and $<0.052 \mu \mathrm{M}$ for the other monosaccharides (Table 1). The LOD for Glc was $0.92 \mu \mathrm{M}$ in Ref. 12. The LOD of amino monosaccharides GlcNAc and GalNAc were decreased by a factor of 65.9 and 44.4, respectively, using the $\mathrm{pH}$ discontinuous solution system. We improved the detection sensitivity of the selected monosaccharides without any deterioration in the separation resolution.

Incidentally, the use of a borate solution at $\mathrm{pH} 9.5$ as a separation solution allowed five neutral monosaccharides to be separated using $300 \mathrm{mM}$ Tris (Fig. S3 in SI). However, the use of a borate solution at $\mathrm{pH} 9.5$ provided a resolution lower than that obtained using a borate solution at $\mathrm{pH} 9.3$.

\section{Conclusion}

The use of the current $\mathrm{pH}$ discontinuous solution system, which is composed of a $200 \mathrm{mM}$ borate solution at $\mathrm{pH} 6.0$ as a sample solution and a $200 \mathrm{mM}$ Tris-borate solution containing $0.5 \mathrm{wt} \%$ $\mathrm{MC}$ at $\mathrm{pH} 9.3$ as a separation solution, is essential for the 
successful separation of five neutral, AMAC-labeled monosaccharides and two amino monosaccharides. We found that the monosaccharide fluorescence intensity was enhanced by the difference in the $\mathrm{pH}$ between a sample solution and a separation solution. We supposed that monosaccharides would be stacked by the difference in the effective mobility of borate ion at $\mathrm{pH}$ values between 6.0 and 9.3. Moreover, we improved the resolution of the five neutral monosaccharides by adding Tris. The sensitivity to the detection of the neutral and amino monosaccharides labeled with AMAC was improved by factors of 19.6 - 48.7 and $44.4-65.9$ using a pH discontinuous solution system without any deterioration in the separation resolution (0.93 - 1.74 and 4.44), respectively.

\section{Acknowledgements}

This work was supported by a Grant-in-Aid for Young Scientists B (No. 21710132) from the Ministry of Education, Culture, Sports, Science and Technology (MEXT), Japan. M. I. acknowledges New Energy and Industrial Technology Development Organization (NEDO) for partly supporting the current work.

\section{Supporting Information}

The effects of the fluorescence intensity of monosaccharides on the $\mathrm{pH}$ of the separation solution using $\mathrm{pH} 7.0$ of the sample solution, the electropherograms of two amino monosaccharides, and the effects of the Tris concentrations on MCE separation using $\mathrm{pH} 9.5$ of the separation solution in a $\mathrm{pH}$ discontinuous solution system are shown in Figs. S1, S2, and S3, respectively. This material is available free of charge on the Web at http://www.jsac.or.jp/analsci/.

\section{References}

1. A. Varki, Glycobiology, 1993, 3, 97.
2. S. Hoffstetter-Kuhn, A. Paulus, E. Gassmann, and H. M. Widmer, Anal. Chem., 1991, 63, 1541.

3. A. Manz, D. J. Harrison, E. M. J. Verpoorte, J. C. Fettinger, A. Paulus, H. Ludi, and H. M. Widmer, J. Chromatogr., 1992, 593, 253.

4. A. T. Wooley and R. A. Mathies, Proc. Natl. Acad. Sci. U. S. A., 1994, 91, 11348.

5. S. C. Jacobson, R. Hergenroder, L. B. Koutny, R. J. Warmack, and J. M. Ramsey, Anal. Chem., 1994, 66, 1107.

6. M. Ueda, Y. Kiba, H. Abe, A. Arai, H. Nakanishi, and Y. Baba, Electrophoresis, 2000, 21, 176.

7. I. Rodriguez, L. J. Jin, and S. F. Li, Electrophoresis, 2000, 21,211

8. H. Nagata, M. Tabuchi, K. Hirano, and Y. Baba, Electrophoresis, 2005, 26, 2247.

9. H. Nagata, M. Tabuchi, K. Hirano, and Y. Baba, Electrophoresis, 2005, 26, 2687.

10. S. Suzuki, N. Shimotsu, S. Honda, A. Arai, and H. Nakanishi, Electrophoresis, 2001, 22, 4023.

11. E. Maeda, K. Hirano, Y. Baba, H. Nagata, and M. Tabuchi, Electrophoresis, 2006, 27, 2002.

12. E. Maeda, M. Kataoka, M. Hino, K. Kajimoto, N. Kaji, M. Tokeshi, J. Kido, Y. Shinohara, and Y. Baba, Electrophoresis, 2007, 28, 2927.

13. E. Maeda, M. Kataoka, S. Yatsushiro, K. Kajimoto, M. Hino, N. Kaji, M. Tokeshi, M. Bando, J. Kido, M. Ishikawa, Y. Shinohara, and Y. Baba, Electrophoresis, 2008, 29, 1902.

14. Z. El Rassi, Electrophoresis, 1990, 20, 3134.

15. U. K. Laemmli, Nature, 1970, 227, 680.

16. H. Nagata, M. Ishikawa, Y. Yoshida, Y. Tanaka, and K. Hirano, Electrophoresis, 2008, 29, 3744.

17. F. Dang, L. Zhang, H. Hagiwara, Y. Mishina, and Y. Baba, Electrophoresis, 2003, 24, 714.

18. Y. Baba, N. Ishimura, K. Samata, and M. Tsuhako, J. Chromatogr., A, 1993, 653, 329.

19. M. Van Duin, J. A. Peters, A. P. G. Kieboom, and H. Van Bekkum, Tetrahedron, 1984, 40, 2901.

20. M. Van Duin, J. A. Peters, A. P. G. Kieboom, and H. Van Bekkum, Tetrahedron, 1985, 41, 3411. 